Fetal Diagnosis ${ }^{\text {and }}$ Therapy
Fetal Diagn Ther 2014;36:154-161

DOI: $10.1159 / 000357841$
Received: October 28, 2013

Accepted after revision: December 4, 2013

Published online: May 17, 2014

\title{
Prenatal Diagnosis of a Placental Infarction Hematoma Associated with Fetal Growth Restriction, Preeclampsia and Fetal Death: Clinicopathological Correlation
}

\author{
Alma Aurioles-Garibay ${ }^{a, b}$ Edgar Hernandez-Andrade ${ }^{a, b}$ Roberto Romero ${ }^{a, c, d}$ \\ Faisal Qureshi, e Hyunyoung Ahn ${ }^{\text {a, b }}$ Suzanne M. Jacques ${ }^{a, e}$ \\ Maynor Garcia ${ }^{a, b}$ Lami Yeo ${ }^{a, b}$ Sonia S. Hassan ${ }^{a, b}$ \\ aPerinatology Research Branch, NICHD/NIH/DHHS, Bethesda, Md. and Detroit, Mich., bepartment of Obstetrics and \\ Gynecology, Wayne State University School of Medicine, Detroit, Mich., 'Department of Obstetrics and Gynecology, \\ University of Michigan, Ann Arbor, Mich., d Department of Epidemiology and Biostatistics, Michigan State University, \\ East Lansing, Mich., and 'Department of Pathology, Harper University Hospital and Department of Pathology, \\ Wayne State University, Detroit, Mich., USA
}

\section{Established Facts}

- Placental infarcts can be manifested as placental cystic lesions.

- Preeclampsia and intrauterine growth restriction can be associated with placental cysts.

\section{Novel Insights}

- Ultrasound characteristics of a placental cystic lesion might suggest the presence of a hematoma within an infarcted placental area.

- Acute fetal hemodynamic deterioration can be related with the progressive development of a hematoma within the cystic lesion.

\section{Key Words}

Stillbirth · Placental lesions · Ultrasound · Doppler velocimetry

\section{Abstract \\ The lesion termed 'placental infarction hematoma' is associ- ated with fetal death and adverse perinatal outcome. Such a lesion has been associated with a high risk of fetal death and abruption placentae. The fetal and placental hemodynamic}

changes associated with placental infarction hematoma have not been reported. This paper describes a case of early and severe growth restriction with preeclampsia, and progressive deterioration of the fetal and placental Doppler parameters in the presence of a placental infarction hematoma.

(c) 2014 S. Karger AG, Basel

R. Romero and E. Hernandez-Andrade contributed equally to this work.

\section{KARGER}

E-Mail karger@karger.com www.karger.com/fdt (c) 2014 S. Karger AG, Base

$1015-3837 / 14 / 0362-0154 \$ 39.50 / 0$
Roberto Romero, MD, DMedSci or Edgar Hernandez-Andrade, MD, PhD Perinatology Research Branch, NICHD, NIH, DHHS Wayne State University/Hutzel Women's Hospital 3990 John R, Box 4, Detroit, MI 48201 (USA)

E-Mail romeror@mail.nih.gov or ehernand@med.wayne.edu 


\section{Introduction}

The lesion termed 'placental infarction hematoma' is associated with fetal death and adverse perinatal outcome. Such a lesion was first described by Bendon [1] when reporting the gross and histopathologic findings of the placenta from 6 pregnant women who had spherical blood clots in the placental mass surrounded by infarcted placental tissue. Five of the 6 cases had a fetal death, and the only surviving fetus was born by emergency cesarean section due to abruptio placentae. The fetal and placental hemodynamic changes associated with placental infarction hematoma have not been reported. This communication describes a case of early and severe growth restriction with preeclampsia and progressive deterioration of the fetal and placental Doppler parameters in the presence of a placental infarction hematoma.

\section{Case Description}

A 20-year-old African-American, gravida 3, para 1, abortion 1, with no previous history of chronic diseases, preeclampsia, or fetal growth restriction in the previous pregnancy, was first seen at 8 weeks of gestation. The fetal size was appropriate for dates. At 19 weeks and 6 days the estimated fetal weight was at the 22nd percentile, there was normal amniotic fluid, and end-diastolic velocity was present in the umbilical artery. There was a bilateral notch in the uterine arteries, and increased pulsatility index (PI). A rounded cystic area measuring $13 \times 14 \mathrm{~mm}$ was observed in the placental mass. Maternal blood pressure was within normal range. At 20 weeks and 5 days, the patient was admitted with severe headache, hypertension, and proteinuria, and was treated with hydralazine and magnesium sulfate. Ultrasound examination showed a live fetus with an estimated fetal weight below the 5th percentile, absent end-diastolic velocity in the umbilical artery, reversed atrial flow in the ductus venosus, and decreased PI in the middle cerebral artery. There was reversal of flow during diastole in the aortic isthmus, bilateral uterine notching, and increased uterine artery

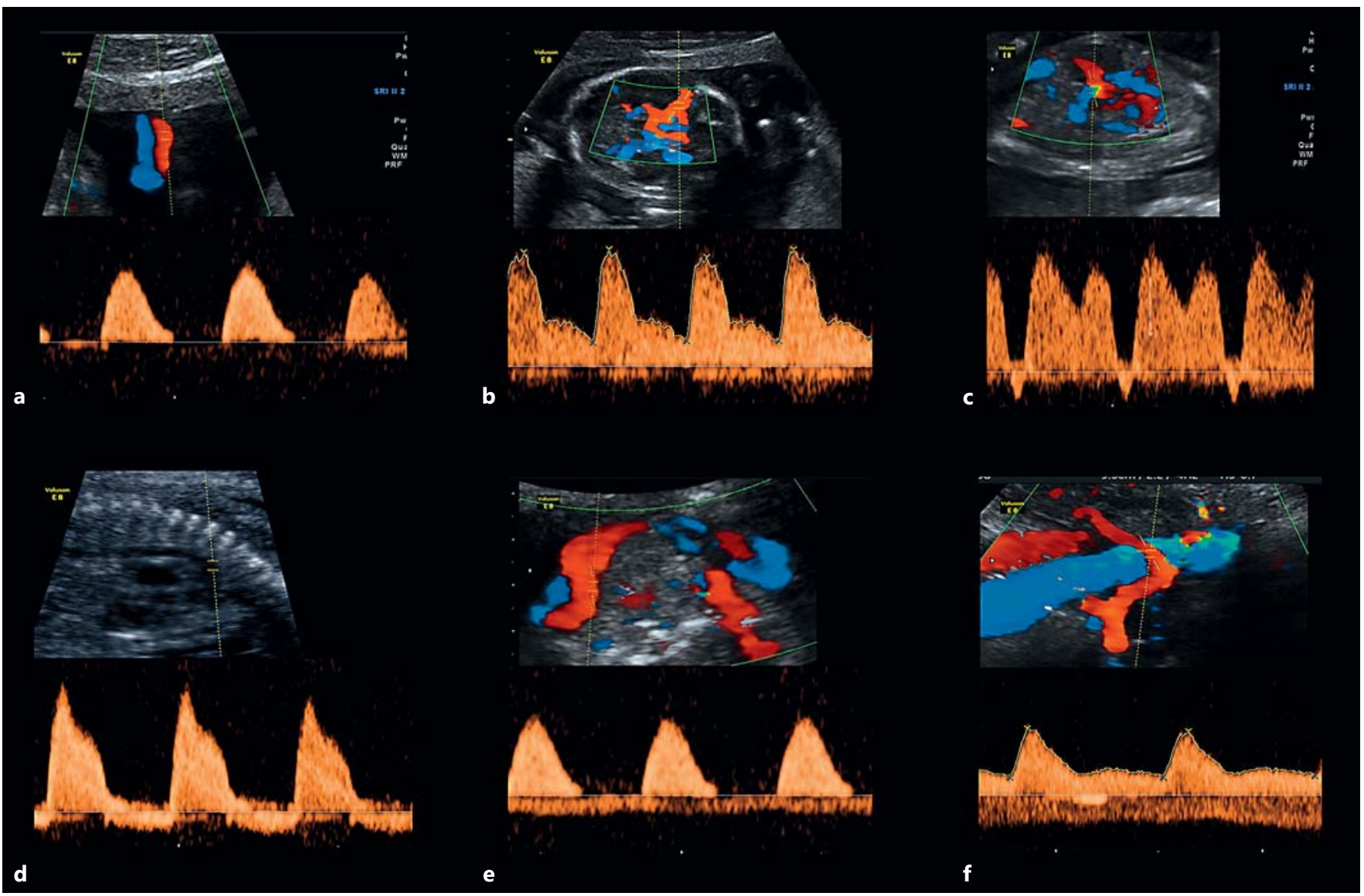

Fig. 1. Doppler parameters at the time of hospital admission $(20$ weeks and 5 days) when fetal growth restriction and preeclampsia were diagnosed. a Absent diastolic velocities in the umbilical artery. b Increased diastolic velocities in the middle cerebral artery. c Reversed atrial velocity in the ductus venosus. d Reversed diastolic velocities in the aortic isthmus. e Continuous flow in the umbilical vein. $\mathbf{f}$ Uterine artery notch. 
PI (fig. 1). The placental cyst measured $14.3 \times 12.7 \mathrm{~mm}$ with an echogenic central area; no blood flow was observed inside or around the placental lesion. The amniotic fluid volume was considered to be within normal range, with a largest vertical pocket of $3.5 \mathrm{~cm}[2]$. Due to the early gestational age, conservative management was undertaken.

During hospitalization, sonographic examinations were performed daily. There was progressive deterioration of Doppler parameters. At 20 weeks and 6 days, the mother remained hypertensive despite treatment with the highest registered blood pressure of $178 / 103 \mathrm{~mm} \mathrm{Hg}$, and proteinuria of $8.2 \mathrm{~g} / 24 \mathrm{~h}$. At 21 weeks and 4 days a fetal death was diagnosed. The last Doppler examination prior to the diagnosis of fetal death done at 21 weeks and 3 days showed signs of severe fetal-placental hemodynamic deterioration such as: reverse diastolic velocities in the umbilical artery $[2,3]$, biphasic umbilical vein pulsations [4-6], bilateral uterine notching and increased uterine artery PI [7-9], reduced middle cerebral artery PI [10], abnormal ductus venosus waveform with reverse atrial flow [11-13], and reduced intermediate flow between the systolic and diastolic components of the waveform [14], reversed diastolic flow in the aortic isthmus [15-18], and coronary artery vasodilatation [19-21] (fig. 2). Representative changes of Doppler interrogation of the different vessels are shown in figure 3 . The placental cyst measured $16 \times 14 \mathrm{~mm}$ with central areas of mixed echodensity (fig. 4a-c); additional small cystic lesions were observed in the placenta (fig. 4d). Labor was induced and the patient delivered a non-viable female weighing $299 \mathrm{~g}$. The autopsy showed a preterm stillborn with no structural anomalies. The mother was discharged 3 days after delivery with normal blood pressure.

\section{Placental Pathology}

The placenta weighed $100 \mathrm{~g}$ and measured $8 \times 7 \times 2 \mathrm{~cm}$. There were three vessels in the umbilical cord. Sections of the placenta showed pale surfaces (fig. 5a, b). A cystic hemorrhagic area with a yellow rim, measuring $3 \times 3 \times 2 \mathrm{~cm}$, was observed involving approximately $20 \%$ of the placenta. Two additional small yellow lesions were noted and confirmed to be infarcts on microscopic examination. The largest lesion was a hematoma surrounded by a rim of infarcted placental tissue. Microscopic evaluation of the placenta also showed persistent muscularization (fig. $5 \mathrm{c}$ ), atherosis (fig. 5d), persistent endovascular trophoblast, mural hypertrophy and thrombi in decidual vessels, as well as abnormal villous morphology including distal villous hypoplasia (fig. 5e) and foci of villous dysmaturity.

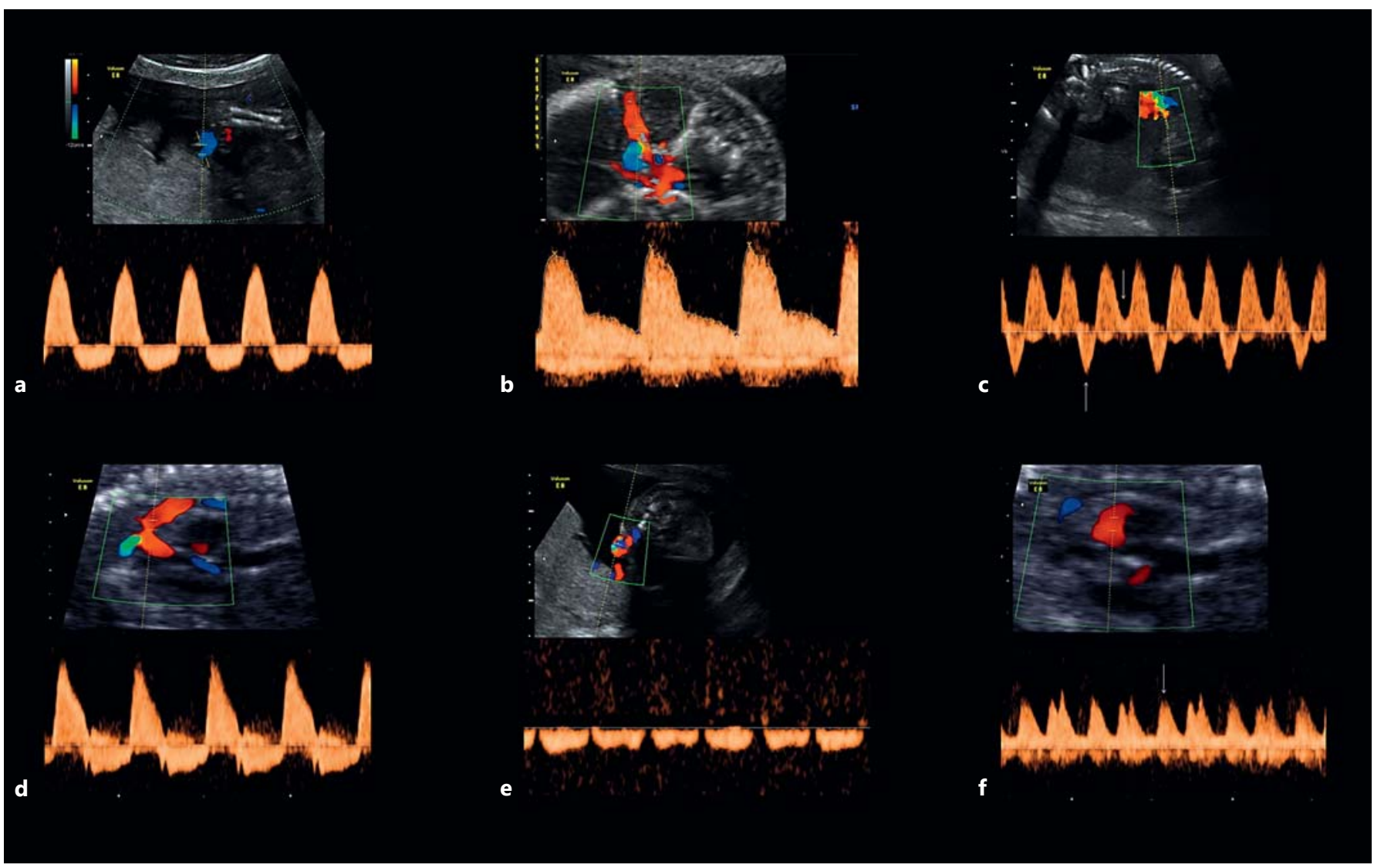

Fig. 2. Doppler parameters before fetal demise (21 weeks and 3 days). a Reversed diastolic velocity in the umbilical artery. b Increased diastolic velocities in the middle cerebral artery. c Reversed atrial flow in the ductus venosus and reduced velocity between the systolic and diastolic components of the waveform. d Reversed diastolic velocities in the aortic isthmus. e Umbilical vein pulsations. $\mathbf{f}$ Visualization of the coronary flow with double peak in the diastolic component. 
Fig. 3. Changes in the pulsatility index of the umbilical artery (UA), middle cerebral artery (MCA), uterine arteries (Ut Art) and ductus venosus (DV) during hospitalization.

Fig. 4. a-c Progressive changes in the echogenicity of the placental lesion in relation to gestational age. The area inside the cyst became more echogenic as gestation progressed (arrows). d Additional small cystic areas are shown.

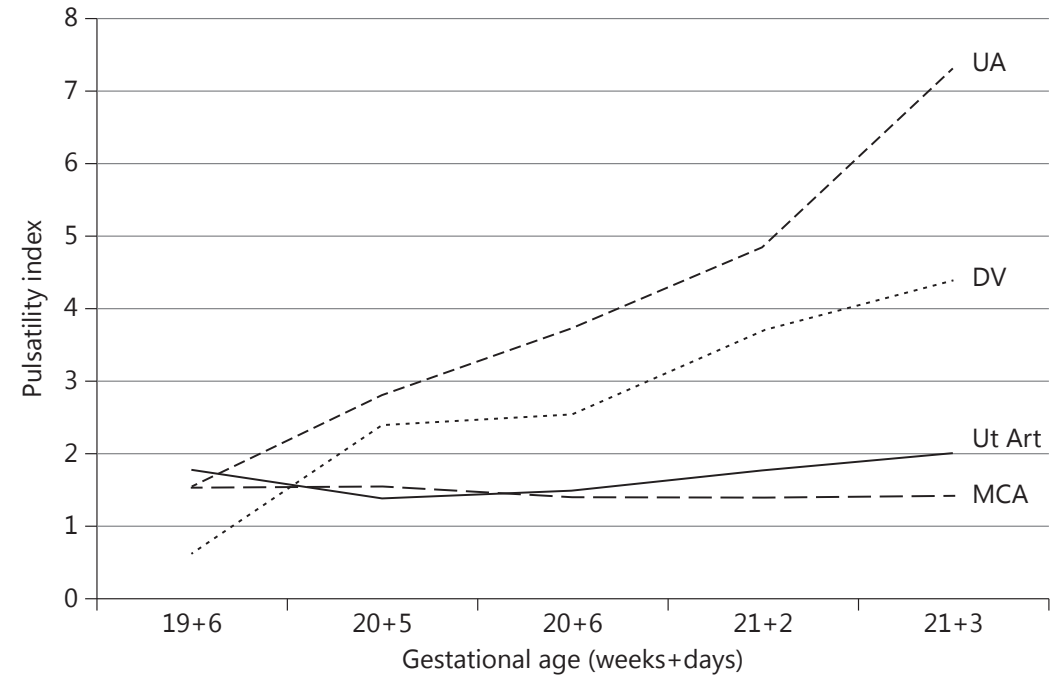

\begin{tabular}{|l|c|c|c|c|c|}
\hline--- UA & 1.56 & 2.81 & 3.74 & 4.86 & 7.34 \\
\hline-- MCA & 1.53 & 1.56 & 1.4 & 1.4 & 1.43 \\
\hline - Ut Art & 1.78 & 1.4 & 1.5 & 1.77 & 2.02 \\
\hline$\cdots \cdot$ DV & 0.64 & 2.4 & 2.56 & 3.73 & 4.4 \\
\hline
\end{tabular}
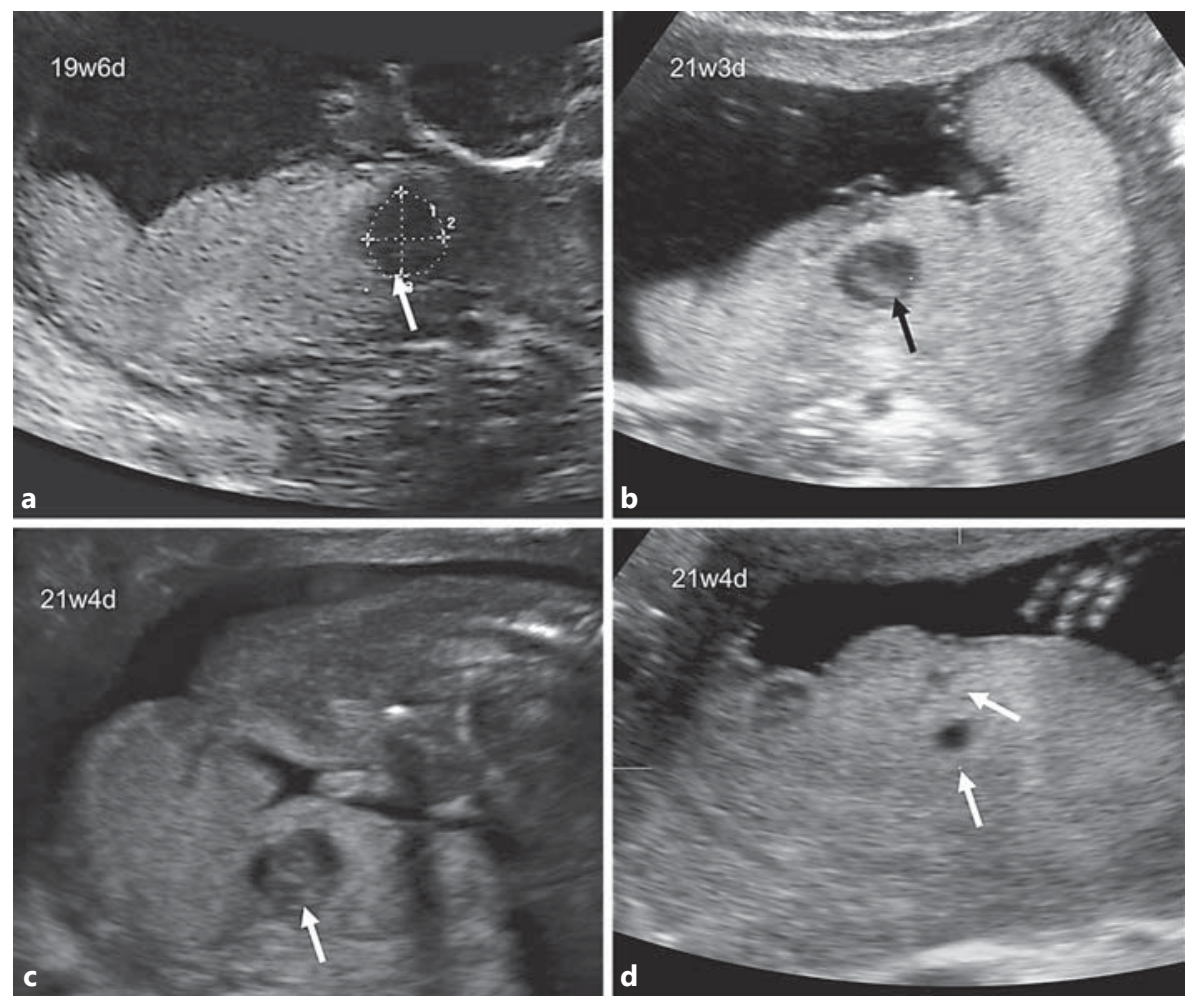


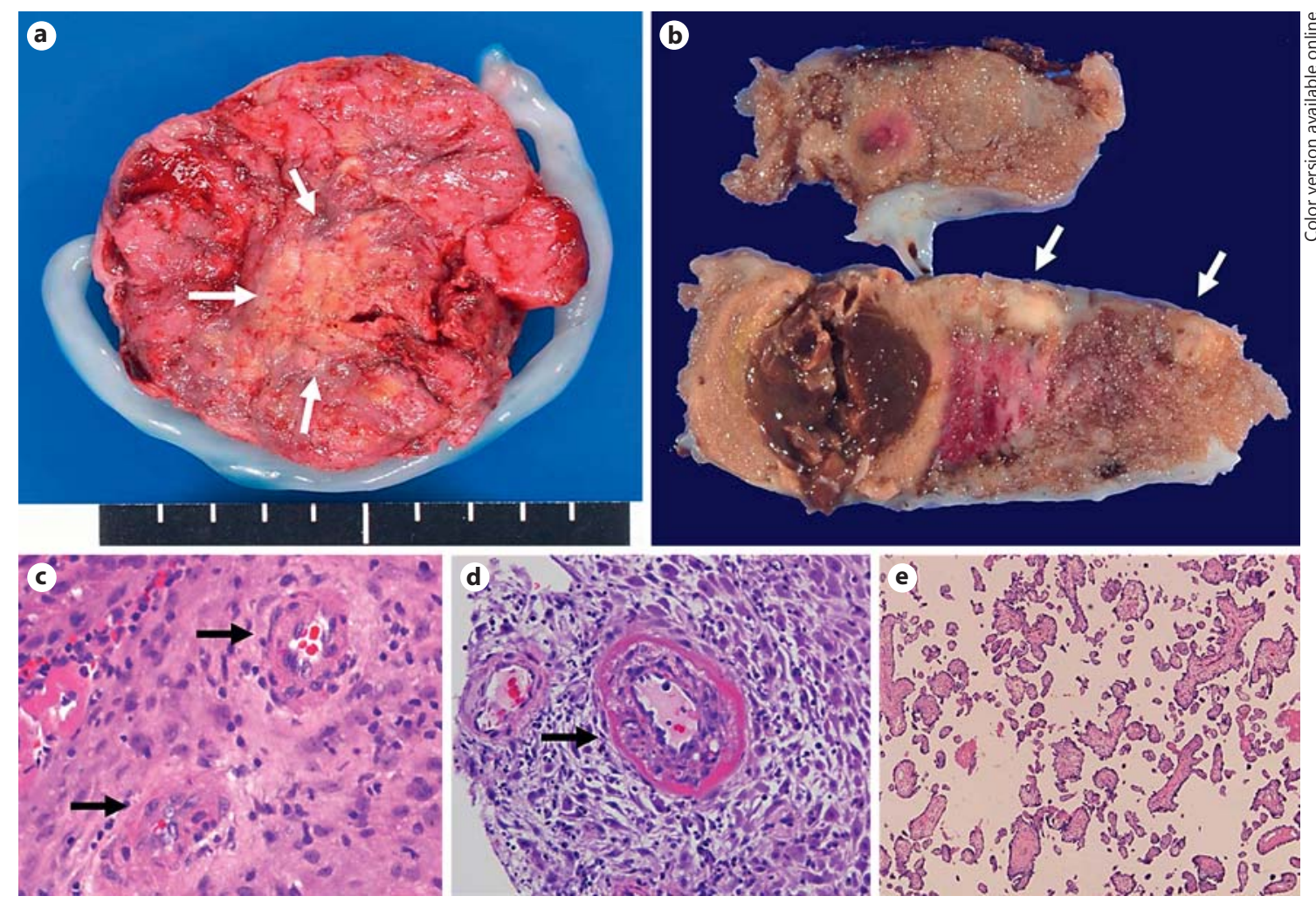

Fig. 5. Pathological examination of the placenta. a The maternal surface shows an ill-defined area (arrows) which coincided with the infarction hematoma. $\mathbf{b}$ Cut sections of the placenta show a large round hemorrhagic lesion surrounded by infarcted placental tissues. Two additional small infarcts (arrows) are also present. c Basal decidual vessels with thick muscularized walls (arrows) and absent physiologic remodeling (persistent muscularization). d Fibrinoid deposition (arrow) in the arterial walls (atherosis). e Decreased number of distal villi with increased syncytial knots and prominent stem villi.

\section{Comment}

This case report shows the rapid deterioration of Doppler parameters in a fetus diagnosed to be growthrestricted and the development of early-onset preeclampsia associated with a placental infarction hematoma. In a period of 6 days, there was cessation of fetal growth and multiple signs of hemodynamic deterioration became apparent. Subsequent sonographic examinations showed worsening of all Doppler parameters consistent with increased impedance to flow in the placenta, abnormal venous Doppler velocimetry, and decreased impedance to flow in the middle cerebral and coronary arteries. The cystic image in the placenta evolved from a predominantly echolucent to a heterogeneous echodense lesion. Acute fetal deterioration may have been associated with the development of the hematoma within the infarcted area of the placenta. The placenta showed extensive lesions of decidual vasculopathy including atherosis and persistent muscularization. Decidual vasculopathy can cause a reduction in uteroplacental blood flow leading to placental ischemia, placental infarcts and lesions of placental underperfusion including, increased syncytial knots, and distal villous hypoplasia [22]. Two smaller infarcts accompanied the infarction hematoma, reinforcing the probability of severe uteroplacental disease. The acute evolution in this case is most likely a result of progressive worsening of uteroplacental disease.

The proposed pathophysiology of placental infarction hematoma is occlusion of a spiral artery leading to a placental infarction and subsequent recanalization of the vessel. This may result in the hematoma within the placental mass [1]. Placental infarction hematoma has been associated with preeclampsia and intrauterine growth restriction (IUGR). However, only a few cases with such conditions have been reported in the literature. Our impression is that this is due to underreporting. The ultrasound appearance shows an echodense region inside an 
echolucent area, which can correspond to a recently formed hematoma. Old hematomas within an infarcted area might not be identified by ultrasound as they tend to appear echolucent with time [23]; a definitive diagnosis can only be made through histopathologic examination of the placenta [24].

Placental infarcts are mainly due to (a) occlusion of spiral arteries by thrombus, or due to under perfusion of secondary to decidual vascular disease [22, 25-28]. Placental infarcts can be documented in approximately $20 \%$ of uncomplicated pregnancies and in 70 and $40 \%$ of patients with severe and mild preeclampsia, respectively [29-31]. Vinnars et al. [30] reported that infarcts involving more than $5 \%$ of the placenta can be observed in $39 \%$ of patients with severe preeclampsia. The association of placental infarctions with acute fetal deterioration was reported by Barclay et al. [32] in a patient at 27 weeks of gestation with acute reduction of amniotic fluid volume, lack of fetal growth, and abnormal fetal heart rate tracing, in the presence of multiple placental cystic areas suggestive of infarcts, which were confirmed after the delivery.

Sonographic images associated with placental lesions include cystic areas [33-35], heterogeneous appearance of the placental mass [36-39], and thick [40] or thin [41] placentas. Cystic areas are frequently observed in association with preeclampsia, growth restriction and fetal demise [31, 42-46]. Fitzgerald et al. [47] reported that welldefined rounded cystic areas in the placenta were associated with a higher risk of preeclampsia and IUGR. The authors referred to this as 'rounded intraplacental haematomas' and reported that more than $50 \%$ of these cystic lesions were associated with placental infarcts reflecting maternal vascular underperfusion. Viero et al. [48] studied the sonographic placental features of 59 fetuses with absent end-diastolic flow in the umbilical artery, and reported cystic images highly suspicious of placental lesions in 43 of 59 pregnancies. Echogenic cystic lesions had a $37 \%$ sensitivity for confirmed villous infarcts, and when combined with abnormal uterine artery Doppler velocimetry, there was a $53 \%$ positive predictive value for fetal death. The authors emphasized the potential value of other imaging techniques of the placenta such as magnetic resonance imaging (MRI) and the possibility of treatment with heparin. Messerschmidt et al. [49] reported the results of MRI examination of the placenta in 50 patients with early IUGR, abnormal umbilical artery Doppler velocimetry or oligohydramnios. The prevalence of placental infarcts with or without hemorrhage was 35 and $89 \%$ for subchorionic thrombi. Fetal death occurred in $36 \%$ of cases and surviving fetuses were delivered at a mean ges- tational age of 29 weeks. The authors proposed that MRI may have the potential for the prenatal diagnosis of placental infarctions in cases of early placental insufficiency.

Detailed sonographic evaluation of the placenta and histopathological confirmation after birth are used to identify lesions associated with preeclampsia, IUGR and adverse short- and long-term perinatal outcome [25, 5058]. The presence of cystic images in the placenta is not uniformly associated with adverse perinatal outcome [59]. Detailed sonographic evaluation of cysts includes evaluation of shape, size and content as well as the absence/presence of blood flow around or inside the cyst. The presence of hypoechogenic images with a regular shape, with a hyperechogenic rim and the lack of demonstrable blood flow, suggests the presence of placental pathology and, specifically, a placental infarction hematoma [60, 61]. MRI may improve the diagnosis of placental cystic structures $[49,62]$. Placental vascular lesions consistent with underperfusion and fetal thrombotic vasculopathy have been associated with abnormal neurodevelopment in surviving fetuses [54, 63, 64].

At present, there is no treatment for placental infarction hematomas. Alkazaleh et al. [65] proposed the use of low-molecular-weight heparin and aspirin when placental lesions suggestive of infarcts are observed in the ultrasound scan. They evaluated pregnant women at 18-20 weeks of gestation with a history of previous fetal death, preeclampsia and/or IUGR. The authors identified 6 patients with echogenic cystic areas in the placenta and abnormal uterine artery Doppler, but still with normal fetal growth; all were treated with low-molecular-weight heparin (dalteparin 5-10,000 units/day s.c.) and $81 \mathrm{mg}$ of aspirin daily. All patients had a live birth (33-37 weeks of gestation). However, the authors did not offer treatment when fetal growth restriction was diagnosed. The study of Alkazaleh et al. [65] is interesting and suggests that the identification of placental lesions with ultrasound in the absence of fetal growth restriction may be amenable to treatment. However, this concept requires additional studies.

\section{Acknowledgments}

This research was supported, in part, by the Perinatology Research Branch, Division of Intramural Research, Eunice Kennedy Shriver National Institute of Child Health and Human Development, National Institutes of Health, Department of Health and Human Services (NICHD/NIH), and, in part, with Federal funds from NICHD, NIH under Contract No. HHSN275201300006C. 


\section{References}

1 Bendon RW: Nosology: infarction hematoma, a placental infarction encasing a hematoma. Hum Pathol 2012:43:761-763.

$>2$ Gudmundsson S, Lindblad A, Marsal K: Cord blood gases and absence of end-diastolic blood velocities in the umbilical artery. Early Hum Dev 1990;24:231-237.

>3 Ferrazzi E, Bozzo M, Rigano S, Bellotti M, Morabito A, Pardi G, Battaglia FC, Galan HL: Temporal sequence of abnormal Doppler changes in the peripheral and central circulatory systems of the severely growth-restricted fetus. Ultrasound Obstet Gynecol 2002;19: 140-146.

-4 Rizzo G, Capponi A, Soregaroli M, Arduini D, Romanini C: Umbilical vein pulsations and acid-base status at cordocentesis in growthretarded fetuses with absent end-diastolic velocity in umbilical artery. Biol Neonate 1995; 68:163-168.

$>5$ Hofstaetter C, Dubiel M, Gudmundsson S: Two types of umbilical venous pulsations and outcome of high-risk pregnancy. Early Hum Dev 2001;61:111-117.

6 Cheema R, Bayoumi MZ, Gudmundsson S: Multivascular Doppler surveillance in high risk pregnancies. J Matern Fetal Neonatal Med 2012;25:970-974.

7 Gudmundsson S, Korszun P, Olofsson P, Dubiel M: New score indicating placental vascular resistance. Acta Obstet Gynecol Scand 2003;82:807-812.

-8 Hernandez-Andrade E, Brodszki J, Lingman G, Gudmundsson S, Molin J, Marsal K: Uterine artery score and perinatal outcome. Ultrasound Obstet Gynecol 2002;19:438-442.

$>9$ Jamal A, Abbasalizadeh F, Vafaei H, Marsoosi V, Eslamian L: Multicenter screening for adverse pregnancy outcomes by uterine artery Doppler in the second and third trimester of pregnancy. Med Ultrason 2013;15:95-100.

-10 Dubiel M, Gudmundsson S, Gunnarsson G, Marsal K: Middle cerebral artery velocimetry as a predictor of hypoxemia in fetuses with increased resistance to blood flow in the umbilical artery. Early Hum Dev 1997;47:177184.

11 Kiserud T, Eik-Nes SH, Blaas HG, Hellevik LR, Simensen B: Ductus venosus blood velocity and the umbilical circulation in the seriously growth-retarded fetus. Ultrasound $\mathrm{Ob}$ stet Gynecol 1994;4:109-114.

-12 Hecher K, Bilardo CM, Stigter RH, Ville Y, Hackeloer BJ, Kok HJ, Senat MV, Visser GH: Monitoring of fetuses with intrauterine growth restriction: a longitudinal study. Ultrasound Obstet Gynecol 2001;18:564-570.

-13 Turan OM, Turan S, Berg C, Gembruch U, Nicolaides KH, Harman CR, Baschat AA: Duration of persistent abnormal ductus venosus flow and its impact on perinatal outcome in fetal growth restriction. Ultrasound Obstet Gynecol 2011;38:295-302.
14 Baschat AA, Turan OM, Turan S: Ductus venosus blood-flow patterns: more than meets the eye? Ultrasound Obstet Gynecol 2012;39: 598-599.

15 Sonesson SE, Fouron JC: Doppler velocimetry of the aortic isthmus in human fetuses with abnormal velocity waveforms in the umbilical artery. Ultrasound Obstet Gynecol 1997;10: 107-111.

16 Fouron JC: The unrecognized physiological and clinical significance of the fetal aortic isthmus. Ultrasound Obstet Gynecol 2003;22: 441-447.

17 Figueras F, Benavides A, Del Rio M, Crispi F, Eixarch E, Martinez JM, Hernandez-Andrade E, Gratacos E: Monitoring of fetuses with intrauterine growth restriction: longitudinal changes in ductus venosus and aortic isthmus flow. Ultrasound Obstet Gynecol 2009;33:3943.

18 Hernandez-Andrade E, Crispi F, BenavidesSerralde JA, Plasencia W, Diesel HF, Eixarch E, Acosta-Rojas R, Figueras F, Nicolaides K, Gratacos E: Contribution of the myocardial performance index and aortic isthmus blood flow index to predicting mortality in preterm growth-restricted fetuses. Ultrasound Obstet Gynecol 2009;34:430-436.

19 Chaoui R: The fetal 'heart-sparing effect' detected by the assessment of coronary blood flow: a further ominous sign of fetal compromise. Ultrasound Obstet Gynecol 1996;7:5-9.

20 Baschat AA, Gembruch U, Gortner L, Reiss I, Weiner CP, Harman CR: Coronary artery blood flow visualization signifies hemodynamic deterioration in growth-restricted fetuses. Ultrasound Obstet Gynecol 2000;16: 425-431.

21 Rizzo G, Capponi A, Pietrolucci ME, Boccia C, Arduini D: The significance of visualising coronary blood flow in early onset severe growth-restricted fetuses with reverse flow in the ductus venosus. J Matern Fetal Neonatal Med 2009;22:547-551.

22 Fox H, Sebire N: Macroscopic abnormalities of the placenta; in Fox H, Sebire N (eds): Pathology of the Placenta. Philadelphia, Saunders Elsevier, 2007, pp 95-146.

23 Nyberg DA, Cyr DR, Mack LA, Wilson DA, Shuman WP: Sonographic spectrum of placental abruption. AJR Am J Roentgenol 1987; 148:161-164.

24 Nguyen D, Nguyen C, Yacobozzi M, Bsat F, Rakita D: Imaging of the placenta with pathologic correlation. Semin Ultrasound CT MR 2012;33:65-77.

25 Brosens I, Renaer M: On the pathogenesis of placental infarcts in pre-eclampsia. J Obstet Gynaecol Br Commonw 1972;79:794-799.

26 Ogge G, Chaiworapongsa T, Romero R, Hussein Y, Kusanovic JP, Yeo L, Kim CJ, Hassan SS: Placental lesions associated with maternal underperfusion are more frequent in earlyonset than in late-onset preeclampsia. J Perinat Med 2011;39:641-652.
27 Romero R, Kusanovic JP, Kim CJ: Placental bed disorders in the genesis of the great obstetrical syndromes; in Pijnenborg R, Brosens I, Romero R (eds): Placental Bed Disorders. New York, Cambridge University Press, 2010, pp 271-289.

28 Kraus FT, Redline RW, Gersell DJ, Nelson DM, Dicke JM: Circulatory Problems: Thrombi and Other Vascular Lesions. Placental Pathology. Washington, American Registry of Pathology, 2004, pp 1-123.

29 Moldenhauer JS, Stanek J, Warshak C, Khoury J, Sibai B: The frequency and severity of placental findings in women with preeclampsia are gestational age dependent. Am J Obstet Gynecol 2003;189:1173-1177.

30 Vinnars MT, Nasiell J, Ghazi S, Westgren M, Papadogiannakis N: The severity of clinical manifestations in preeclampsia correlates with the amount of placental infarction. Acta Obstet Gynecol Scand 2011;90:19-25.

31 Krielessi V, Papantoniou N, Papageorgiou I, Chatzipapas I, Manios E, Zakopoulos N, Antsaklis A: Placental pathology and blood pressure's level in women with hypertensive disorders in pregnancy. Obstet Gynecol Int 2012; 2012:684083.

32 Barclay D, Evans K, Fox R: Ultrasound-diagnosed placental infarction in a woman with recurrent fetal growth restriction. J Obstet Gynaecol 2005;25:200-201.

33 Harris RD, Cho C, Wells WA: Sonography of the placenta with emphasis on pathological correlation. Semin Ultrasound CT MR 1996; 17:66-89.

34 Brown DL, DiSalvo DN, Frates MC, Davidson KM, Genest DR: Placental surface cysts detected on sonography: histologic and clinical correlation. J Ultrasound Med 2002;21:641646.

35 Proctor LK, Whittle WL, Keating S, Viero S, Kingdom JC: Pathologic basis of echogenic cystic lesions in the human placenta: role of ultrasound-guided wire localization. Placenta 2010;31:1111-1115.

36 Chen KH, Chen LR, Lee YH: Exploring the relationship between preterm placental calcification and adverse maternal and fetal outcome. Ultrasound Obstet Gynecol 2011;37: 328-334.

37 Theophilou G, Sahashrabudhe N, Martindale EA, Heazell AE: Correlation between abnormal placental appearance at routine second trimester ultrasound scan and histological examination of the placenta after birth. J Obstet Gynaecol 2012;32:760-763.

38 Soto E, Romero R, Kusanovic JP, Ogge G, Hussein Y, Yeo L, Hassan SS, Kim CJ, Chaiworapongsa T: Late-onset preeclampsia is associated with an imbalance of angiogenic and anti-angiogenic factors in patients with and without placental lesions consistent with maternal underperfusion. J Matern Fetal Neonatal Med 2012;25:498-507. 
39 Whitten AE, Romero R, Korzeniewski SJ, Tarca AL, Schwartz AG, Yeo L, Dong Z, Hassan SS, Chaiworapongsa T: Evidence of an imbalance of angiogenic/antiangiogenic factors in massive perivillous fibrin deposition (maternal floor infarction): a placental lesion associated with recurrent miscarriage and fetal death. Am J Obstet Gynecol 2013;208: 310e1-310e311.

40 Raio L, Ghezzi F, Cromi A, Nelle M, Durig P, Schneider H: The thick heterogeneous (jellylike) placenta: a strong predictor of adverse pregnancy outcome. Prenat Diagn 2004;24: 182-188.

-41 Shukunami K, Nishijima K, Kurokawa T, Tajima K, Kamitani N, Yoshida Y, Kotsuji F: A small-angled thin edge of the placenta predicts abnormal placentation at delivery. J Ultrasound Med 2005;24:331-335.

-42 Laurini R, Laurin J, Marsal K: Placental histology and fetal blood flow in intrauterine growth retardation. Acta Obstet Gynecol Scand 1994;73:529-534.

-43 Salafia CM, Minior VK, Pezzullo JC, Popek EJ, Rosenkrantz TS, Vintzileos AM: Intrauterine growth restriction in infants of less than thirty-two weeks' gestation: associated placental pathologic features. Am J Obstet Gynecol 1995;173:1049-1057.

44 Roberts DJ, Post MD: The placenta in pre-eclampsia and intrauterine growth restriction. J Clin Pathol 2008;61:1254-1260.

-45 Cooley SM, Donnelly JC, Walsh T, McMahon C, Gillan J, Geary MP: The impact of ultrasonographic placental architecture on antenatal course, labor and delivery in a low-risk primigravid population. J Matern Fetal Neonatal Med 2011;24:493-497.

-46 Vedmedovska N, Rezeberga D, Teibe U, Melderis I, Donders GG: Placental pathology in fetal growth restriction. Eur J Obstet Gynecol Reprod Biol 2011;155:36-40.

47 Fitzgerald B, Shannon P, Kingdom J, Keating S: Rounded intraplacental haematomas due to decidual vasculopathy have a distinctive morphology. J Clin Pathol 2011;64:729-732.
8 Viero S, Chaddha V, Alkazaleh F, Simchen MJ, Malik A, Kelly E, Windrim R, Kingdom JC: Prognostic value of placental ultrasound in pregnancies complicated by absent end-diastolic flow velocity in the umbilical arteries. Placenta 2004;25:735-741.

49 Messerschmidt A, Baschat A, Linduska N, Kasprian G, Brugger PC, Bauer A, Weber M, Prayer D: Magnetic resonance imaging of the placenta identifies placental vascular abnormalities independently of Doppler ultrasound. Ultrasound Obstet Gynecol 2011;37: 717-722.

50 Jauniaux E, Campbell S: Ultrasonographic assessment of placental abnormalities. Am J Obstet Gynecol 1990;163:1650-1658.

-51 Rodriguez JG, Porter HJ, Andrews HS, Soothill PW: Placental lesions: is growth a predictor of bad outcome? Fetal Diagn Ther 1997; 12:163-166.

52 Kojima K, Suzuki Y, Makino A, Murakami I, Suzumori K: A case of massive subchorionic thrombohematoma diagnosed by ultrasonography and magnetic resonance imaging. Fetal Diagn Ther 2001;16:57-60.

53 Redline RW, Minich N, Taylor HG, Hack M: Placental lesions as predictors of cerebral palsy and abnormal neurocognitive function at school age in extremely low birth weight infants $(<1 \mathrm{~kg})$. Pediatr Dev Pathol 2007;10: 282-292.

54 Redline RW: Placental pathology: a systematic approach with clinical correlations. Placenta 2008;29(suppl A):S86-S91.

55 Yeo L, Ananth C, Vintzileos AM: Placental abruption; in Bloomer D, Arulkumaran S (eds): The Global Library of Women's Medicine. 2008:10.3843/GLOWM.10122.

56 Brosens I, Pijnenborg R, Vercruysse L, Romero R: The 'great obstetrical syndromes' are associated with disorders of deep placentation. Am J Obstet Gynecol 2011;204:193-201.
57 Romero R, Whitten A, Korzeniewski SJ, Than NG, Chaemsaithong P, Miranda J, Dong Z, Hassan SS, Chaiworapongsa T: Maternal floor infarction/massive perivillous fibrin deposition: a manifestation of maternal antifetal rejection? Am J Reprod Immunol 2013;70: 285-298.

58 Tuuli MG, Odibo AO: Ultrasound imaging and Doppler studies of the placenta; in Kay $\mathrm{HH}$, Nelson DM, Wang Y (eds): The Placenta from Development to Disease. Oxford, Blackwell Publishing, 2011, pp 122-130.

59 Reis NS, Brizot ML, Schultz R, Nomura RM, Zugaib M: Placental lakes on sonographic examination: correlation with obstetric outcome and pathologic findings. J Clin Ultrasound 2005;33:67-71.

60 Kofinas A, Kofinas G, Sutija V: The role of second trimester ultrasound in the diagnosis of placental hypoechoic lesions leading to poor pregnancy outcome. J Matern Fetal Neonatal Med 2007;20:859-866.

-61 Blair E, de Groot J, Nelson KB: Placental infarction identified by macroscopic examination and risk of cerebral palsy in infants at 35 weeks of gestational age and over. Am J Obstet Gynecol 2011;205:124 e121-e127.

62 Dekan S, Linduska N, Kasprian G, Prayer D: MRI of the placenta - a short review. Wien Med Wochenschr 2012;162:225-228.

63 Perrone S, Toti P, Toti MS, Badii S, Becucci E, Gatti MG, Marzocchi B, Picardi A, Buonocore G: Perinatal outcome and placental histological characteristics: a single-center study. J Matern Fetal Neonatal Med 2012;25(suppl 1):110-113

64 Redline RW: Severe fetal placental vascular lesions in term infants with neurologic impairment. Am J Obstet Gynecol 2005;192:452457.

65 Alkazaleh F, Viero S, Simchen M, Walker M, Smith G, Laskin C, Windrim R, Kingdom J: Ultrasound diagnosis of severe thrombotic placental damage in the second trimester: an observational study. Ultrasound Obstet Gynecol 2004;23:472-476. 